\title{
Impact of coronavirus disease pandemic on surgery for lung cancer in a provincial city in Japan
}

\author{
Taichiro Goto \\ Lung Cancer and Respiratory Disease Center, Yamanashi Central Hospital, Yamanashi, Japan \\ Correspondence to: Taichiro Goto, MD. Lung Cancer and Respiratory Disease Center, Yamanashi Central Hospital, Yamanashi 400-8506, Japan. \\ Email: taichiro@1997.jukuin.keio.ac.jp.
}

Submitted Jul 13, 2020. Accepted for publication Jul 29, 2020.

doi: $10.21037 /$ jtd-20-2427

View this article at: http://dx.doi.org/10.21037/jtd-20-2427

Since the first detection of coronavirus disease (COVID-19) in Japan in January 2020, the number of patients with COVID-19 has rapidly increased. In mid-April, the government declared a state of emergency, which lasted until late May. On May 25, the state of emergency was lifted, and restrictions on movement were gradually eased to resume social and economic activities. Following this, the number of patients remained low, but it started increasing again by the end of June, raising concern. As effective vaccines and drugs for COVID-19 are yet to be found, long-term management plans are necessary to prevent the spread of infection. In treatment of other patients, "new clinical practice models" are also necessary in order to accommodate both COVID-19 and non-COVID-19 patients.

Recently, the incidence of lung cancer has steadily increased in Japan and worldwide (1). Lung cancer progresses asymptomatically, necessitating regular screening for early detection (2). In fact, $80-90 \%$ of lung cancer patients who underwent surgery at our hospital were detected through prior screening. In our country, lung cancer is commonly screened using chest X-ray, but computed tomography (CT) is also an option for patients upon request. In 2011, two studies reported that chest X-ray alone is insufficient for detecting and reducing the mortality of lung cancer; therefore, the introduction of CT screening is essential $(3,4)$. However, in our country, CT screening has broken down due to the COVID-19 pandemic. In this paper, we compared lung cancer patients who underwent surgery at our hospital from April to June 2020 with those from the previous years (April to June 2017 to 2019) to examine the epidemiological effects of the pandemic on surgical treatment of lung cancer.

At our hospital, which is a core hospital in a provincial city of Yamanashi, we perform surgery for 160 to 170 cases of lung cancer yearly. In our course of the pandemic, the number of lung cancer patients who underwent surgery from April to June 2020 remained constant, compared with that in previous years, at 38 patients (Table 1). In terms of lung cancer detection, the number of patients who underwent chest X-ray or CT screening significantly decreased (Table 1). Although no significant difference was observed in the distribution of age, sex, or histology, there were significantly more patients with advanced stage in this year than in the previous years (Table 1). A possible reason for the lack of decrease in the number of lung cancer patients undergoing surgery in this year is the refrainment of nearby smaller-sized hospitals from providing treatment and surgery in the time of the pandemic. The changes in case distribution clearly indicated an increased number of patients with advanced stage due to the collapse of the CT screening system.

In fact, all major provincial screening facilities in Yamanashi were closed from April to May under the state of emergency. Despite gradual opening of these facilities in June, only a small number of people is presently undergoing screening. Possible reasons for them to refrain from undergoing screening this year include the lack of urgency for screening and the risk of contracting COVID-19 in a crowded and closed space of a screening facility. Needless to say, avoiding the risk of contracting COVID-19 is important. However, it is questionable whether exercising extreme caution with COVID-19 justifies refraining from undergoing screening for other diseases, especially lung 
Table 1 Changes in surgery for lung cancer at our hospital from April to June 2017 to 2020

\begin{tabular}{|c|c|c|c|c|c|}
\hline Factors & 2017 & 2018 & 2019 & 2020 & $P$ value \\
\hline Age, years (mean $\pm S D)$ & $69.8 \pm 7.1$ & $69.5 \pm 9.1$ & $69.5 \pm 8.3$ & $69.6 \pm 8.4$ & NS \\
\hline Sex & & & & & NS \\
\hline Male & 19 & 24 & 19 & 25 & \\
\hline Events leading to detection & & & & & $<0.05$ \\
\hline Chest X-ray screening & 7 & 12 & 10 & 4 & \\
\hline CT screening & 20 & 19 & 14 & 1 & \\
\hline Subjective symptoms & 1 & 2 & 2 & 29 & \\
\hline 0 & 2 & 2 & 1 & 0 & \\
\hline IA & 16 & 20 & 15 & 6 & \\
\hline IB & 5 & 6 & 7 & 8 & \\
\hline$\| A$ & 3 & 4 & 3 & 11 & \\
\hline IIB & 1 & 2 & 1 & 4 & \\
\hline IIIA & 1 & 1 & 1 & 5 & \\
\hline IIIB & 1 & 0 & 0 & 3 & \\
\hline IVA & 1 & 0 & 1 & 1 & \\
\hline Proportion of surgical cases & 40.5 & 39.8 & 39.7 & 26.0 & $<0.05$ \\
\hline
\end{tabular}

Histological typing was performed according to the World Health Organization classification (3rd edition), and clinical staging was performed according to the International Union Against Cancer Tumor-Node-Metastasis classification (8th edition). Continuous variables were presented as mean \pm standard deviation (SD), and one-way analysis of variance and the Tukey-Kramer multiple comparison test were used to detect significant differences between groups. Chi-square tests were used to compare the categorical data between groups. $P$ values less than 0.05 in the two-tailed analyses were considered to denote statistical significance. NS, not statistically significant.

cancer, which is the leading cause of cancer death $(1,2)$.

At our hospital, approximately $40 \%$ of lung cancer patients on their first visit usually undergo surgery (Table 1), which is consistent with the average proportion in our country. In contrast, this proportion substantially decreased to $26.0 \%$ for April to June 2020. If the system of providing CT screening continues to collapse, more patients may be found to have more advanced lung cancer, and the proportion of operable patients among all lung cancer patients may further decrease. A consequent rapid increase in deaths due to lung cancer in the near future is a concern.

In Japan, many municipal governments postponed cancer screening when the state of emergency was declared nationwide in April, and It is still unknown when screening will be resumed. Preventive measures against cancer are extremely important for reducing cancer-related deaths. Resumption of cancer screening requires development of a screening system without creating the three Cs (i.e., a 
closed space with poor ventilation, a crowded place with many people nearby, and a close-contact setting such as close-range conversation), as well as implementation of basic preventive measures against infection, such as handsanitizing, mask-wearing, and physical distancing. Drastic changes in the system may be necessary for improving or redesigning waiting areas and flow of people undergoing screening, dispersing these people via time setting (screening at weekend, early morning, and late-evening), or restricting the number of people. Moreover, it is important to fully explain the risk of contracting COVID-19 and the implemented preventive measures against the spread of infection to people undergoing screening and to make them understand the benefits and risks of undergoing cancer screening.

Although conventional lung cancer screening is mainly performed using imaging modalities such as CT and chest X-ray, development of new diagnostic modalities appropriate for the current situation is also important $(5,6)$. If lung cancer can be diagnosed using serum samples, sputum, and breath samples, lung cancer screening can be safely performed without the risk of infection (7-9). Given the current circumstances, promising diagnostic techniques should be rapidly applied to clinical practice. To this end, a drastic paradigm shift in all stages, such as basic researches, clinical trials, and social system reforms, may be necessary.

Because measures against new coronavirus infection are expected to be implemented for a long time, it is important to establish a cancer screening system in compliance with the "new lifestyle". From the perspective of clinicians involved in the treatment of lung cancer, we believe there is an urgent need to provide opportunities for people to safely undergo cancer screening while taking appropriate preventive measures against the spread of infection.

\section{Acknowledgments}

Funding: None.

\section{Footnote}

Provenance and Peer Review: This article was a free submission to the journal. The article did not undergo external peer review.

Conflicts of Interest: The author has completed the ICMJE uniform disclosure form (available at http://dx.doi. org/10.21037/jtd-20-2427). The author has no conflicts of interest to declare.

Ethical Statement: The author is accountable for all aspects of the work in ensuring that questions related to the accuracy or integrity of any part of the work are appropriately investigated and resolved. Written informed consent was obtained from the patient for the publication of this study.

Open Access Statement: This is an Open Access article distributed in accordance with the Creative Commons Attribution-NonCommercial-NoDerivs 4.0 International License (CC BY-NC-ND 4.0), which permits the noncommercial replication and distribution of the article with the strict proviso that no changes or edits are made and the original work is properly cited (including links to both the formal publication through the relevant DOI and the license). See: https://creativecommons.org/licenses/by-nc-nd/4.0/.

\section{References}

1. Global Burden of Disease Cancer C, Fitzmaurice C, Dicker D, et al. The Global Burden of Cancer 2013. JAMA Oncol 2015;1:505-27.

2. Mesa-Guzman M, Gonzalez J, Alcaide AB, et al. Surgical Outcomes in a Lung Cancer-Screening Program Using Low Dose Computed Tomography. Arch Bronconeumol 2020. [Epub ahead of print].

3. National Lung Screening Trial Research T, Aberle DR, Adams AM, et al. Reduced lung-cancer mortality with low-dose computed tomographic screening. $\mathrm{N}$ Engl J Med 2011;365:395-409.

4. Oken MM, Hocking WG, Kvale PA, et al. Screening by chest radiograph and lung cancer mortality: the Prostate, Lung, Colorectal, and Ovarian (PLCO) randomized trial. JAMA 2011;306:1865-73.

5. Wadowska K, Bil-Lula I, Trembecki L, et al. Genetic Markers in Lung Cancer Diagnosis: A Review. Int J Mol Sci 2020;21:4569.

6. Goto T, Hirotsu Y, Amemiya K, et al. Distribution of circulating tumor DNA in lung cancer: analysis of the primary lung and bone marrow along with the pulmonary venous and peripheral blood. Oncotarget 2017;8:59268-81.

7. Kort S, Brusse-Keizer M, Gerritsen JW, et al. Improving lung cancer diagnosis by combining exhaled-breath data and clinical parameters. ERJ Open Res 2020;6:002212019.

8. Asakura K, Kadota T, Matsuzaki J, et al. A miRNA- 
based diagnostic model predicts resectable lung cancer in humans with high accuracy. Commun Biol 2020;3:134.

9. Goto T, Hirotsu Y, Nakagomi T, et al. Detection of

Cite this article as: Goto T. Impact of coronavirus disease pandemic on surgery for lung cancer in a provincial city in Japan. J Thorac Dis 2020;12(9):5056-5059. doi: 10.21037/jtd-202427 tumor-derived DNA dispersed in the airway improves the diagnostic accuracy of bronchoscopy for lung cancer. Oncotarget 2017;8:79404-13. 